\title{
A Contrastive Analysis of Animal Metaphor in English and Persian
}

\author{
Marveh Miri \\ Department of Language and Literature, Islamic Azad University, Larestan Branch, Iran \\ E-mail: Marveh_miri@yahoo.com \\ Afshin Soori (Corresponding author) \\ Department of Language and Literature, Islamic Azad University, Larestan Branch, Iran \\ E-mail: Afshin_soori@yahoo.com
}

Doi:10.7575/aiac.alls.v.6n.2p.160

URL: http://dx.doi.org/10.7575/aiac.alls.v.6n.2p. 160
Received: $10 / 12 / 2014$

Accepted: 06/02/2015

\begin{abstract}
Learning a second language for Iranian students may not be simple at all parts, and it may be difficult for them, especially in some parts that is different from their first language principles. One of these parts is Metaphor, which is different in most languages according to their culture and history. This article is a kind of comparative study which aimed to describe some differences between English and Persian interpretation of animal metaphor. We have three categorization for animal metaphor and different examples according to cultures of both languages.
\end{abstract}

Keywords: Animal metaphor, Contrastive analysis, Error analysis, Figurative language

\section{Introduction}

Teaching and learning a second language, is not as easy as what it seems. It may be difficult for some learners. Some learners may work strong at some parts, skills and components, and they may feel weak at other different parts. This problem may have several reasons, one of them is first language interference. There are two kinds of interference: positive, which facilitate second language learning; and negative interferences which cause students to make different errors.

Interference is the process of carrying over the speech habits of the native language into a foreign or second language, by which errors are generated (Yarmohammadi, 2002). The topic of "first language interference" had an unusual history in second language acquisition research and practice. Error cause by negative interferences led scholars to argue about contrastive analysis (Krashen, 1981).

"Contrastive analysis (CA) is the systematic study of a pair of languages in order to identify their structural differences and similarities, usually for translation and teaching purposes" (Keshavarz, 2011). The same kind of definition is provided by Fallahi (1991) that says," Contrastive analysis is a branch of linguistics that brings two language systems together, sets them against each other, and seeks to define the similarities and the differences between them". As the term Contrastive implies, it is more about differences between languages than in their likenesses.

One of the troublesome areas of EFL for Iranian students and especially novice translators is the figurative use of language. Figurative language is a set of literary devices that authors use to bring the reader into the writing. The literary devices use language in such a way that what is being said is different from the actual literal meaning of the words. It helps the reader to get a clearer picture of what's happening. Some common types of figurative language are: simile, metaphor, personification, and etc. (Faghih, 2001).

This study focus on the differences between animal metaphor interpretation in English and Persian. Metaphor is one of the figurative uses of language which definitely plays a significant role in language learning. Metaphor is a type of comparison between two objects that are not alike but have some similarities. It is similar to simile, but it doesn't use the words "like" or "as."

\section{Metaphor and its categorization}

By definition, a metaphor involves a relationship of comparison between different propositions which are believed to have some kind of similarity. Hence a metaphor is composed of three parts:

1) Topic: the phenomenon or proposition we are talking about.

2) Image: the phenomenon or proposition which is utilized to clarify the meaning of the topic.

3) Point of similarity: the domain, or characteristic which originally belongs to the image

The correct understanding of any metaphor depends on the correct identification of the topic, image, and point of similarity (Faghih, 2001). 
He is the topic.

Mouse is the image.

Timid is the point of similarity.

There are two types of metaphor that is necessary to know in translation: Dead and live metaphors. Dead is a kind of metaphors which because of over usage have been a part of everyday speech. Live metaphors are those which is not common in use and you have to interpret them according to context and situation (Shuttleworth \& Abdullah, 2013).

One of the theories of interpreting metaphors is that of Beekman \& Callow (as cited in Faghih, 2001) which is based on the implicit information. They believe that the implicit information of a metaphor is based on three types, in other words, there are three ways of interpreting a metaphor:

1) The immediate context in the printed matter, i.e. the preceding and following parts of the passage which is the easiest way of interpreting metaphors.

2) The more remote context utilized which is abundant in literature and especially in historical literary works, and refers to the kind of interpretation, where the immediate context is of no use and in order to grasp the point of view, the reader has to examine the communication situation.

3) The cultural context which is of focal importance for the present research.

So for translation, students need to consider several things in different context.

Here, there are three categorization in the view of using the name of animals and their meaning.

1. Animal metaphors in both languages are the same in form and meaning.

2. Animal metaphors which are different in their form but have the same meaning.

3. Animal Metaphors which exist just in English.

Here, there are some examples for each category which is cited in English Idioms in use and Persian idioms and also online dictionaries (English Idioms \& Idiomatic Expressions, n.d.).

\section{Animal metaphors in both languages are the same in form and meaning}

1) English: Cat and $\operatorname{dog}$ life = If people lead a cat and dog life, they are always arguing.

Persian: Mesle sag o gorbe hastan.

Cat $\&$ Dog $=$ Sag va Gorbeh $=$ Arguing

2) English: Crocodile tears $=$ an insincere display or grief.

Persian: ashke temsah.

Crocodile $=$ Temsah $=$ False tears

3) English: Eagle eyes = keen eyesight.

Persian: cheshmane oghab.

Eagle $=$ Oghab $=$ keen eyesight

4) English: Eat like a bird = eat very little.

Persian: andaze gonjeshk mikhorad.

Bird $=$ Gonjeshk $=$ little

\section{Animal metaphors which are different in their forms but have the same meaning}

1) English: A little bird told me = If someone doesn't want to say where they got some information from, they can say that a little bird told me.

Persian: kalaqe khabar avord. (Raven)

2) English: Cat got your tongue? = If someone asks if the cat has got your tongue, they want to know why you are silent.

Persian: Moosh zaboneto khordeh? (Mouse)

3) English: Work like a Dog = work so hard.

Persian: Messe khar kar kardan. (Donkey)

4) English: She is a bookworm = a person who reads a lot. Persian: Khar khan ast. (Donkey)

5) English: Hungry enough to eat a horse = very hungry.

Persian: Mitoonam yek gav ro bokhoram. (Cow)

6) English: Chicken out of = If you chicken out of something, you decide not to do something because you are afraid. Persian: Boz del ast. (Goat)

\section{Animal Metaphors which exist just in English}

1) English: Butterflies in your stomach $=$ the nervous feeling.

Persian $\neq$

Translation: Delshooreh dashtan.

2) English: Smell like a rat

Persian $\neq$

Translation: Mashkook mizanad. 
3) English: Kill two birds with one stone.

Persian $\neq$

Translation: Ba ye sang do neshan.

4) English: you look fishy.

Persian $\neq$

Translation: Mashkook mizani.

5) English: Raining cats and dogs.

Persian $\neq$

Translation: Be sheddat baran baridan.

In translation and interpretation of metaphors two main things are important. The first one is culture, and the second one is the main salient characteristic. Since two different languages have different cultures and history, students would make some errors in translation. So it is necessary to get familiar with different aspects of second language learning (Goatly, 2006).

There are different books which can help EFL and ESL students in translating metaphors and they surely related to their culture and history. But when it is not possible to find a good or suitable book or references, it is better to find out the salient characteristic of a topic or animal. Translators can search for evidences in a text in order to find the meaning of the idiom (Faghih, 2001). Here are the most common interpretations of some animals in Persian:
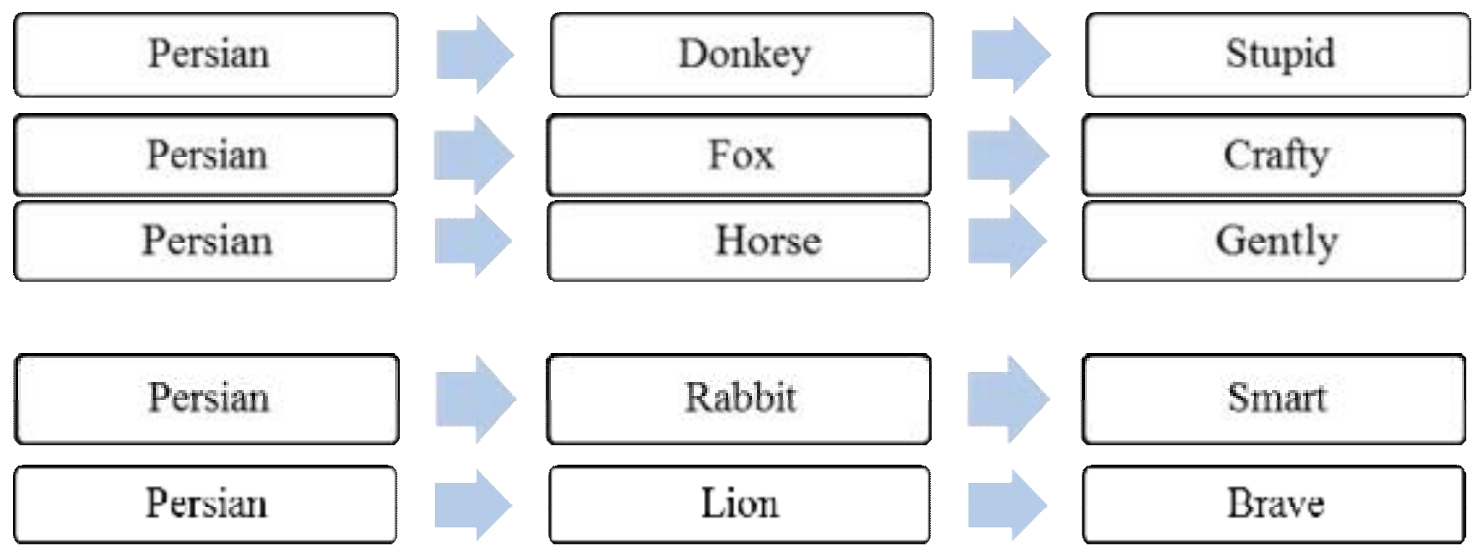

\section{Conclusion}

The aim of contrastive analysis is to find differences and similarities between two languages in order to help learners to perform better (Yarmohammadi, 2002). A contrastive analysis would help EFL and ESL students to analyze and think about each part of English learning deeply and use them wisely to pretend interferences errors.

Metaphor is one part of language learning which may cause some problems for teachers and learners. The only way to get along with these kinds of errors is to study different books about metaphors and use them regularly in order to do better in this part. As it is clear all parts of metaphor interpretation do not related to the cultural differences and a good translator and a wise learner can get the meaning of them through the text and context which they are talking and using metaphors.

\section{References}

English Idioms \& Idiomatic Expressions. (n.d.). Retrieved from Learn English Today: http://www.learn-englishtoday.com/idioms/idiom-categories/animals/html

Faghih, E. (2001). A contrastiveanalysisof the interpretations of animal metaphors in persianand english. The Journal of Humanities.

Fallahi, M. (1991). Contrastive linguistic and Analysis of Error. Tehran: Iran university press.

Goatly, A. (2006). Humans, Animals, and Metaphors. Society and Animals. Retrieved from www.animalsandsociety.com/assets/library/594_sa1414.

Keshavarz, M. (2011). Contrastive Analysis and Error Analysis. Tehran: Rahnama Press.

Krashen, S. D. (1981). The Role of the First Language in Second Language Acquisition. In Second Language Acquisition and Second Language Learning. Southern California. Retrieved from www.sdkrashen.com

Shuttleworth, M., \& Abdullah, S. (2013). Metaphors in the translation of english technical texts into malay: a preliminary study. Journal of Asian Scientific Research, 6(3), 608-629.

Yarmohammadi, L. (2002). A contrastive Analysis of Persian and English. Tehran: Payame Noor University Press. 